\title{
Data-driven digital advertising: benefits and risks of online behavioral advertising
}

\author{
Simone Aiolfi, Silvia Bellini and Davide Pellegrini \\ Economics and Business Management, University of Parma, Parma, Italy
}

\begin{abstract}
Purpose - The research aims to investigate how individuals can be persuaded to make purchases through repeated and personalized messages. Specifically, the study proposes a framework of the potential benefits and risks of the online behavioral and data-driven digital advertising (OBA), which can help researchers and practitioners to better understand shopping behavior in the online retailing setting. In addition, the research focuses on the role of privacy concerns in affecting avoidance or adoption of OBA.

Design/methodology/approach - The authors apply a structural equation modeling (SEM) approach with partial least square (PLS) regression method to test the research hypotheses through data coming from a structured questionnaire.

Findings - OBA is a controversial type of advertising that activates opposing reactions on consumers' perspective. Specifically, acceptance of the OBA is positively related to relevance, usefulness and credibility of the personalized advertisements, while the intention to avoid personalized ads is strictly related to the privacy concerns. Consequently, OBA acceptance and avoidance affected the click intention on the ad and the behavioral intention that are decisive for the success of data-driven digital advertising.

Originality/value - Prior research came up with complex theoretical frameworks that explain antecedents of OBA focusing only on ethical issues in marketing, on the effectiveness of a single OBA campaign or on how to create a successful advertising campaign. However, no study focuses on the intended or actual behavior of shoppers. Specifically, filling the gap in the existing literature, our research applies an SEM approach to identify both benefits and risks and the antecedents of the actual behavior of individuals in terms of actual purchases promoted by OBA.
\end{abstract}

Keywords Online behavioral advertising, Digital advertising, Data-driven advertising, Personalized advertising, Privacy concern, Behavioral intention

Paper type Research paper

\section{Introduction}

According to eMarketer, in 2020, digital advertising spending in the world will increase by $2.4 \%$ compared to 2019, reaching an amount of 332.84 billion dollars, representing 36.11 billion dollars less spending than pre-pandemic forecast (eMarketer, 2020). However, it represents around half of global advertising spending, and in some countries, including the United Kingdom (UK), China, Norway, Canada, The United States of America (USA) and the Netherlands, digital has already become the main advertising medium. On the other hand, in countries such as Latin America and Southeast Asia, investments continue to delay, and hence traditional methods are prevalent (eMarketer, 2019).

Recent developments in online tracking and profiling technologies have changed the way of communicating to people, and specially to customers, allowing the targeting and personalization process in real time while a user browses the Internet (Moore et al., 2015;

(C) Simone Aiolfi, Silvia Bellini and Davide Pellegrini. Published by Emerald Publishing Limited. This article is published under the Creative Commons Attribution (CC BY 4.0) licence. Anyone may reproduce, distribute, translate and create derivative works of this article (for both commercial and noncommercial purposes), subject to full attribution to the original publication and authors. The full terms of this licence may be seen at http://creativecommons.org/licences/by/4.0/legalcode

Data-driven digital advertising

1089

Received 9 October 2020 Revised 15 February 2021 1 April 2021

Accepted 8 April 2021 
IJRDM

49,7
Sinclair, 2016). In this sense, technology allows firms to target consumers based on their general interests, thanks to the analysis of the editorial content of the web page on which the ad would be displayed (Goldfarb and Tucker, 2011). Thus, to personalize and target advertisements, firms can use data collected through the online behavior of users. Researchers identify this phenomenon as the so-called online behavioral advertising (OBA). In literature, there are several definitions of OBA, but all of them identify two common characteristics: the monitoring and tracking of consumer online behavior and the use of data collected to target ads (Boerman et al., 2017; Varnali, 2019). This innovative type of advertising is based on tracking users in order to make insights about their potential interests and convey relevant and personalized advertisements related both to the preferences of the users and their online behavior.

The theoretical background of OBA research is highly fragmented. Many studies focus on the effects of the OBA and how to measures acceptance and resistance to the OBA (McDonald and Cranor, 2010; Ur et al., 2012; Smit et al., 2014; Boerman et al., 2017). However, the perceptions about the OBA seem to be divergent. Specifically, studies indicate that the OBA is characterized by a continuous contrast between benefits and risks.

As far the benefits are concerned, the OBA makes advertisements more relevant to consumers who, seeing a relevant and personalized ad for them, are less likely to avoid the advertising (McDonald and Cranor, 2010; Ur et al., 2012). Conversely, as far as risks are concerned, individuals consider the collection and use of personal data as an invasive tactic that leads to the rise of negative perceptions in terms of the loss of privacy (Ur et al., 2012; Smit et al., 2014; Moore et al., 2015; Phelan et al., 2016; Summers et al., 2016; Varnali, 2019).

According to ethical problems in marketing studied by the acquisition-transaction theory (Baek and Morimoto, 2012), the likelihood of a consumer purchasing a product or service depends on the comparison between perceived benefits and perceived risks and costs (Baek and Morimoto, 2012; Plangger and Montecchi, 2020). This process refers to the so-called privacy calculus described as a rational analysis of the balance between benefits and costs of disclosing personal data to a firm (Culnan and Armstrong, 1999; Plangger and Montecchi, 2020). Similarly, the social exchange theory (Emerson, 1976) suggests that people evaluate social exchanges in terms of costs and rewards. Thus, people will change their behavior and participate in social exchanges only when the reward exceeds the cost (Schuman et al., 2014). Therefore, it becomes crucial to understand how and in which measure consumers value both the benefits of the OBA and its costs in order to accept or avoid it. Consequently, the acceptance or the avoidance of the OBA will affect consumer's actual purchasing behavior.

The research aims to investigate how individuals can be persuaded to purchase a product or service through personalized messages. Specifically, the work attempts to come out with a structural equation model, which can help researchers and practitioners to better understand the shopping behavior in the online retailing setting with respect to the potential benefits and risks of the online behavioral and data-driven digital advertising.

The paper is organized as follows. First, a literature review about online behavioral advertising and the factors influencing data-driven digital advertising is presented. Secondly, we present our hypotheses that lead to our conceptual framework of OBA and the methodology used. Then, we present and discuss our findings. Finally, the last two sections are devoted to conclusion and implications, limitations and future directions.

\section{Theoretical background}

Traditional advertising has long been conceived as a type of persuasive advertising aimed at changing the habits of individuals. However, advertising is a very dynamic field that will continue to evolve (Taylor and Carlson, 2021). The Internet and new media have changed 
individuals' habits and the way they interact with advertising messages, leading to a new definition of advertising by Kerr and Richards (2020). As presented in the review about the advertising by Taylor and Carlson (2021), the new definition of advertising by Kerr and Richards (2020) emerged: "advertising is paid, owned, and earned mediated communication activated by an identifiable brand and intent on persuading the consumer to make some cognitive, affective, or behavior change, now or in the future." The authors stated that digital growth allows the disruption of traditional advertising leading to five major consequences: "(1) changes in consumer empowerment and connectedness; (2) multi-platform media consumption and the inclusion of paid, owned, and earned media in advertising decisions; (3) changes to advertising practice; (4) the regulatory imperatives of a global marketplace; and (5) the meaning and scope of advertising research" (Kerr and Richards, 2020).

Thus, digital technologies and digital environment have transformed the customer journey, and they are rapidly changing the environment within which firms operate, reducing information asymmetries between customers and sellers as well as changing the overall marketing strategies (Wedel and Kannan, 2016; Kannan, 2017). For these reasons, firms are now challenging the new perspective of digital marketing defined by the American Marketing Association (AMA) as a set of "activities, institutions, and processes facilitated by digital technologies for creating, communicating and delivering value for customers and other stake-holders" [1]. Another interesting definition of digital marketing is proposed by Wedel and Kannan (2016) and Kannan (2017) who referred to digital marketing as "an adaptive, technology-enabled process by which firms collaborate with customers and partners to jointly create, communicate, deliver, and sustain value for all stakeholders." According to the authors, digital marketing is not only the marketing of products and services using digital touch points but it describes the process of using digital technologies to acquire customers and build customer preferences, promote brands, retain customers and increase sales (Wedel and Kannan, 2016; Kannan, 2017). For a deeper understanding of the topics about digital marketing, see the work proposed by Kannan (2017) on the framework for research in digital marketing in which the authors highlight some of the research issues on digital environment to keep the review of extant work in digital marketing as well as to uncover the gaps that exist in the marketing literature and suggest new topics for exploration (Kannan, 2017). Therefore, as far as the digital environment is concerned, a new paradigm has emerged and has led to a revolution in the way companies act in terms of investments, promotions and measurements (Wedel and Kannan, 2016; Kannan, 2017).

On the one hand, the new paradigm, known as "Advertising 3.0," is characterized by the transformation of the concept of value, which refers to psychological aspects and characteristics of experience and relationships rather than to its economic utility. According to Mardegan et al. (2016), Advertising 3.0 is characterized by the end of the centrality of the product as an engine of operational marketing, and the company does not focus only on the definition and development of the product but also on the subjective and social experience with the product and the opportunities connected to it. This leads to advertisements not focused on quality and price of a product but on the experience of product usage, which is then shared with its own social network (Mardegan et al., 2016).

On the other hand, Advertising 3.0 is characterized by the ongoing technological evolution, which gives companies the possibility to manage new tools that allow them to better understand and communicate with individuals as well as measure advertising results and returns on investments (Mardegan et al., 2016). Since new technologies allow companies to identify their target audience and monitor and collect data about the behavior of individuals, the new advertisements are more customizable and engaging as well as better equipped to understand consumers' behaviors and intention. Furthermore, in the past, the effectiveness of the investments on traditional advertising was unknown, since one bought a space without knowing if it had received attention and from how many people. Conversely,
Data-driven digital advertising 
IJRDM

49,7

1092 digital advertising is data-centric and performance-based, that is, it manages to acquire data that allow to measure in a concrete way the effectiveness of the campaign, and optimize it over time (Brettel et al., 2015; Ghose and Todri, 2015; Mardegan et al., 2016). Online clickstream, messaging, word-of-mouth (WOM), transaction and location data have greatly reduced the variable cost of data collection resulting in unprecedented volumes of data called "the oil" of the digital economy by Wedel and Kannan (2016). Wedel and Kannan (2016) in their work synthetized the development of data-driven analytics in marketing through a critical examination of marketing analytics methods. The authors traced the historical development of data, examining several applications to structured and unstructured data generated within or external to a firm, and reviewing their potential to support marketing decision and to provide deeper insights on consumer behavior.

In addition to its benefits, digital advertising has also faced several problems and challenges. One of the main concern is the "Ad Fraud," or advertising fraud, namely, the practice of defrauding any form of online advertising, altering the performance of advertising campaigns using methods that can artificially inflate profits by the scammer, by restricting the advertisers' budget (Jain, 2007).

Despite these potential negative effects, companies have started to manage data-driven digital advertising in order to intercept potential users while browsing online, or to intercept online those who have previously shown interest in the companies' product offerings, in order to convince them to complete an action (i.e. the purchase). Originally, technology made it possible to target consumers based on their general interests, thanks to inferences made by analyzing the editorial content of the web page on which the ad would be displayed (Goldfarb and Tucker, 2011). Recent developments in online tracking and profiling technologies have made the targeting and personalization process not only possible but also instantaneous, as it occurs in real time while a user browses the Internet (Moore et al., 2015; Sinclair, 2016).

For instance, clickstream data, defined by Guo and Sismeiro (2020) as "the electronic record of Internet usage collected by Web servers or third-party services," provide firms with the record of a site visitor's journey on a website (Sismeiro and Bucklin, 2004; Bucklin and Sismeiro, 2009; Guo and Sismeiro, 2020). Online tracking allows firms understand the individuals' decisions to continue browsing or to exit the website, the length of time that the visitor spends viewing each page, how much activity people engage in at the website, how many pages are visited as well as what customers are doing while browsing, that is, if they filter for products rather than exploring for additional products (Sismeiro and Bucklin, 2004; Guo and Sismeiro, 2020).

Therefore, detailed actions and online behaviors can better indicate purchase tendencies and improve the prediction of purchases. For a more detailed contribution to the research on customers' path information and individual-level online buying behavior, see Guo and Sismeiro (2020) who developed the concepts of sequences of customers' viewing behaviors to describe customers' paths and predict purchases.

Thus, to personalize and target advertisements, firms can use data collected through the online behavior of users: web pages visited, articles read, videos watched and searches in search engines. Furthermore, besides web browsing data or search history, online behavior can include media consumption data, app usage data, purchases, ad click-through, usergenerated content (e.g. emails, posts on social networks) as well as data generated by the use of sensors in mobile devices, by robotic technologies or even by biometric user information tracked by wearable devices (Lamberton and Stephen, 2016).

Researchers identify the new type of data-driven digital advertising as the so-called "Online Behavioral Advertising" (OBA), defined by Boerman et al. (2017) as "the practice of monitoring people's online behavior and using the information collected to show them individually targeted advertisements.” In literature, there are several definitions of OBA, but all of them identified two common characteristics: the monitoring and tracking of consumer 
online behavior and the use of data collected through target ads. In addition, in order to find the boundaries of the OBA domain, an online behavior can be qualified, according to Varnali (2019), as "that behavior that can be monitored and recorded as data linked to an individual profile and that can be used to personalize an online advertisement."

In a nutshell, this type of advertising is based on tracking users in order to obtain insights about their potential interests and convey relevant and personalized advertisements related both to the preferences of the users and their online behavior. For example, when two users enter a website at the same time, each of them would receive an ad different from the one displayed by the other.

Among the specific formats of OBA, retargeting and banner morphing (or morphing banner advertising) are the most used.

Retargeting is an OBA format that allows firms to reach users who have previously visited their site, while they see another, targeting an advertising message not only to a potentially interested customer but also to those who may already have planned activities to search for information about products or services the advertiser aims to sell (Sahni et al., 2019). Tracking takes place through a code element often called pixels that is placed on the website in which the ad is displayed; in this way as soon as a user opens the site, the code releases a cookie in the user's browser, which, from that moment, will track the online behaviors allowing user to be reached with its own advertisements while the user continues browsing other sites (Mardegan et al., 2016; Sahni et al., 2019). Prior studies state that retargeting, also known as remarketing or behavioral retargeting, is often aimed at suggesting users to finalize a purchase by targeting consumers who have visited the advertiser's website in the past but did not make a purchase (Bleier and Eisenbeiss, 2015b; Sahni et al., 2019; Li et al., 2020). Specifically, Li et al. (2020) suggest companies to actively engage in e-commerce cart retargeting (ECR), defined as "a form of digital behavioral retargeting wherein online reminder ads are delivered to consumers who had carted products but left without purchasing."

Banner morphing is a complement to context matching or behavioral targeting that, according to Urban et al. (2014), "enables a website to learn, automatically and optimally, which banner advertisements to serve to consumers to maximize click-through rates, brand consideration, and purchase likelihood.” Morphing differs from other ad formats because, according to this approach, banners are matched to consumers based on posterior probabilities of latent segment membership, cognitive styles, rather than past behavior. Furthermore, the cognitive-style segments are inferred from the analysis of consumers' clickstreams and the automatic identification of morph-to-segment matches (Urban et al., 2014; Liberali et al., 2017). For all these reasons, prior studies state that banner morphing is more effective on web pages that are relevant to consumers, namely, the banner advertisement is more effective when it is customized for a cognitive-style segment (Urban et al., 2014; Liberali et al., 2017).

The theoretical background of OBA research is highly fragmented, and many of the OBA studies use a variety of theories from different disciplines, such as social and cognitive psychology, communication and marketing to better understand and explain this type of practice. Several studies focus on the effects of the OBA and how to measures acceptance and resistance to the OBA (McDonald and Cranor, 2010; Ur et al., 2012; Smit et al., 2014; Boerman et al., 2017). However, the perceptions about the OBA seem to be divergent. Specifically, previous studies state that the OBA is characterized by a continuous contrast between benefits and risks.

As far as the benefits are concerned, the theory of uses and gratifications was mainly used to identify OBA's potential benefits (Sutanto et al., 2013; Ozcelik and Varnali, 2019). Specifically, the OBA makes advertisements more relevant to consumers who, seeing a relevant and personalized ad for them, are less likely to avoid the advertising (McDonald and 
IJRDM 49,7

1094
Cranor, 2010; Ur et al., 2012). Literature states the centrality of an ad's relevance as a reason why the OBA may excel in performance when compared to non-personalized ads (Bellman et al., 2013). This assumption is grounded in the elaboration likelihood model (Petty and Cacioppo, 1986), so that the more personal and relevant a message, the greater the probability that the message will be noticed, making it more effective (Petty et al., 1983). By tracking and profiling, it is possible to gain insights about the general interests and needs of individuals, allowing making an advertisement at the right time and in the right place, resulting in a more relevant exposure. That is, with advanced big data technology, firms now are able to target specific customers using more relevant ads, communicate and create the needed reactions more effectively.

Prior research considered advertising personalization as a dominant strategy that became important not only for marketers but also for consumers who are expected to react positively because of personal experience (Monem and Nagy, 2021). Personalization advertising, in fact, allows advertisers to be more precisely able to look into the needs of the individuals, providing benefits and positive user experience (Monem and Nagy, 2021). Thus, it turns out to be an effective tool to build a relationship with the targeted consumer.

Recent research focuses on trait-based personalization, a new form of advertising for which advertisers show content that is in line with the individual user's personality traits (Winter et al., 2021). For example, according to this innovative approach, a user open to new experiences would be exposed to an ad that focuses on novel features of a product, while a person with low openness to experience would be exposed to an ad that highlights the traditional features of a product (Winter et al., 2021). This form of customization can be less obvious than traditional forms of personalized advertising and, therefore, more persuasive due to the great difficulty in recognizing it as targeted advertising.

Therefore, OBA is much more effective than non-targeted advertising, resulting in an increasing click-through rates and purchases (Bellman et al., 2013; Boerman et al., 2017). However, these effects depend on factors controlled by the advertiser, such as the information used to personalize the ad and the transparency of the advertiser, and on those controlled by consumers, such as trust in the advertiser, the perceived usefulness of the ad, the feeling of intrusion and concerns about privacy (Boerman et al., 2017). Specifically, the lack of control over personal data and the loss of privacy are considered the main concerns on the acceptance and effectiveness of the OBA: consumers who are most concerned about privacy are less likely to trust online businesses in protecting their data (Turow et al., 2009; McDonald and Cranor, 2010; Baek and Morimoto, 2012; Lambrecht and Tucker, 2013; Van Doorn and Hoekstra, 2013; Yang, 2013; Lee et al., 2015; Moore et al., 2015). Conversely, individuals who have few privacy concerns, who are usually more likely to share their information, respond more positively to the OBA (Lee et al., 2015).

Therefore, as far as risks are concerned, individuals consider the collection and use of personal data as an invasive tactic that leads to the rise of negative perceptions (Ur et al., 2012; Smit et al., 2014; Moore et al., 2015; Phelan et al., 2016; Summers et al., 2016; Varnali, 2019). These negative perceptions are supported both by the information boundary theory (Sutanto et al., 2013) that suggests how people find the collection and use of personal information intrusive and therefore perceive it as a risk, and by the social presence theory for which the social presence refers to the feeling of being with someone else in a mediated communication (Phelan et al., 2016). Specifically, when a computer collects users' data, it generates negative feelings that are common to those that arise when a person spies on people while surfing the Internet (Phelan et al., 2016). According to Moore et al. (2015), consumers often find the OBA invasive, annoying, disturbing and capable of violating social norms. Therefore, the more the individuals become increasingly concerned about the OBA, the more they tend to change their online behavior when they understand that their data are being collected (McDonald and Cranor, 2010). Besides the two theories above, the other most used theories to explain the 
potential costs of the OBA are the persuasion knowledge model (Van Noort et al., 2013; Ham and Nelson, 2016), the psychological reactance theory (Tucker, 2014; Aguirre et al., 2015; Bleier and Eisenbeiss, 2015a, b) and the privacy calculus theory (Gironda and Korgaonkar, 2018).

In addition, according to ethical problems in marketing studied by the acquisitiontransaction theory (Baek and Morimoto, 2012), the likelihood of a consumer purchasing a product or service depends on the comparison between perceived benefits and perceived risks and costs (Baek and Morimoto, 2012). This process refers to the so-called privacy calculus described as a rational analysis of the balance between benefits and costs of disclosing personal data to a firm (Culnan and Armstrong, 1999; Plangger and Montecchi, 2020). Similarly, the social exchange theory (Emerson, 1976) suggests that people evaluate social exchanges in terms of costs and rewards. Thus, people will change their behavior and participate in social exchanges only when the reward exceeds the cost (Schuman et al., 2014).

As a result, based on these theories, consumers could only accept the OBA if they were to perceive that the benefits of increasing the relevance of online ads are greater than the corresponding cost to their privacy (Baek and Morimoto, 2012; Schumann et al., 2014).

\section{Research objectives and proposed OBA framework}

Over time, advertisers are beginning to consider the OBA as one of the most important ways to reach their target audience. In addition, on the theoretical basis, the OBA is aimed at conveying more relevant advertisements to users. However, the collection of information and its use is often hidden, thus creating ethical problems, as consumers are unaware of the mechanisms underlying the OBA (Boerman et al., 2017). Despite the positive aspects of this data-driven digital advertising technique - namely relevance and personalization collecting, using and sharing users' personal data inevitably lead to privacy problems (Boerman et al., 2017). Therefore, although several theories have been used to enrich the knowledge about the antecedents of the OBA, it becomes crucial to understand how and in which measure consumers value both the benefits of the OBA (e.g. relevance, credibility, perceived usefulness) and its costs (e.g. privacy concerns) in order to accept or avoid the OBA.

The research aims to investigate how individuals can be persuaded to purchase a product or service through personalized messages. Specifically, the study aims to identify the potential contents able to provide value for individuals, and therefore capable of influencing them. Thus, it may result in a behavioral intention to purchase the products promoted by the OBA. In addition, the research focuses on the role of privacy concerns in terms of affecting avoidance or adoption of this new type of advertising.

Finally, the end purpose of our work is to test our proposed OBA framework (Figure 1) and to come out with a structural equation model, which can help researchers and practitioners to better understand shopping behavior in the online retailing setting as far as the potential benefits and risks of the online behavioral and data-driven digital advertising are concerned.

Specifically, our conceptual framework is based on the following hypotheses.

\section{Relevance-acceptance}

Over time, several studies have led to the understanding of how advertising content can influence consumer responses to OBA. Many studies agree that the relevance of an ad is one of the main reasons for which OBA could excel in performance compared with non-personalized ads. According to Bellman et al. (2013), changes in the relevance of an ad affect the attention and exposure to it. This is consistent with the elaboration likelihood model, so that the more personal and relevant a massage is, the more likely the message is to be noticed, making it more effective (Petty et al., 1983). Through tracking and profiling, it is possible to make inferences about the general interests and needs of individuals, allowing 


\section{IJRDM 49,7}
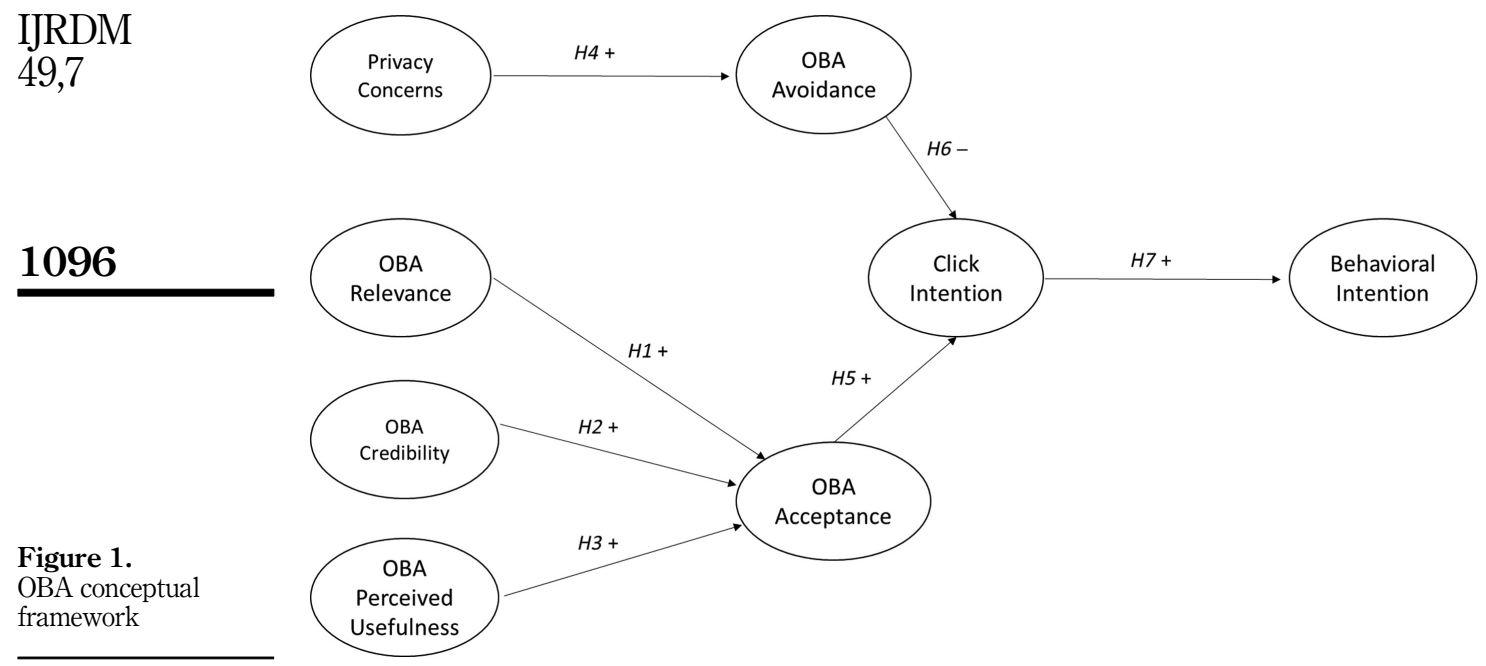

personalized displaying ads at the right time, with the result that its exposure will be more relevant. Specifically, according to Boerman et al. (2017), the level of personalization is based on the types of personal data that are used to target the ad and the amount of information that is used. Bleier and Eisenbeiss (2015b) investigated the effectiveness of content customization in banner ads by considering the interaction between timing and ad placement. Specifically, the authors state that banners with a high degree of content customization are the most effective if a user has just visited the advertiser's online store, but quickly lose effectiveness as the time distance from the last visit increases. Conversely, banners with an average degree of customization are less effective initially, but over time, they outperform banners with a high degree of customization.

Thus, people are more motivated to devote their cognitive effort required to assess the true value of a product when engagement is high; the opposite when engagement is low (Petty et al., 1983). These considerations lead to the following hypothesis:

H1. The higher the level of relevance of the OBA, the higher the level of acceptance of the OBA.

\section{Credibility - acceptance}

Credibility is essential in the success of personalized ads, and consists in seeing the ads as reliable and capable of having a significant role in guiding the purchases. Literature states that OBA is more effective than non-targeted advertising, but its effects depend both on consumer-controlled factors and on advertiser-controlled factors. The latter mainly refer to the information used to customize the advertiser's ad and transparency, namely, to the credibility of the ad (Boerman et al., 2017).

Most research investigated how the strategy of gathering information at sites influences the acceptance and possible effectiveness of OBA. Advertisers should therefore consider the level of ad personalization, as ads perceived as too personal might be seen as too intrusive and consequently lead to lower level of acceptance of the ad. Tucker (2014) showed that giving users more control over their personal information could increase credibility of the ad and the likelihood that user would accept and click on personalized ads. 
In addition, advertisers should be more transparent, benefiting from open communication in data collection and use in order to personalize ads. Specifically, Miyazaki (2008) and Jai et al. (2013) state that negative consumer reactions to the use of cookies can be reduced by an information statement. Therefore, a more credible ad should not only focus on informing users about this practice but also try to reduce their concerns, especially among older and less educated people (Smit et al., 2014). Thus, as stated by Aguirre et al. (2015), gathering information openly can lead to a higher level of OBA acceptance and more click intentions in response to personalized ads.

Therefore, a more credible message may encourage users to more likely to accept the OBA message, resulting in the following hypothesis:

H2. The higher the level of credibility of the OBA, the higher the level of acceptance of the OBA.

\section{Perceived usefulness - acceptance}

According to literature, the effectiveness of OBA depends on factors controlled by the advertiser such as the information used to personalize the ad and the advertiser transparency (Boerman et al., 2017) and factors related to the consumer. Among the latter factors, perceived usefulness of the ads, by developing advertisements that reflect interests in a comprehensive way, is the main factor affecting the acceptance of the OBA (Bleier and Eisenbeiss, 2015a). Davis (1989) defined perceived usefulness as "the degree to which a person believes that using a particular system would enhance his or her job performance." As far as OBA is concerned, perceived usefulness refers to the extent the users believe OBA and relevant personalized ads will help them perform better based on their own purposes. This is consistent with Davis (1989) who states how perceived usefulness and perceived ease of use are the two most important causes of people's attitude to accept or reject information technology. Thus, on OBA perspective, a digital data-driven advertising high in perceived usefulness, in turn, is one for which a user believes in the existence of a positive acceptance-performance relationship. This relationship is strengthened by the level of personalization, the type of personal data used to target the ad and the amount of information used. Therefore, acceptance of the OBA is positively related to the usefulness of the ad, so we propose the following hypothesis:

H3. The higher the level of perceived usefulness of the OBA, the higher the level of acceptance of the OBA.

\section{Privacy concerns - avoidance}

Research has shown how privacy issues play a crucial role in the effectiveness of the OBA. Specifically, concern for privacy is one of the central problems for the digital data-driven advertising, as it creates negative perceptions in users as well as feeling of vulnerability (Sutanto et al., 2013). According to Moore et al. (2015), consumers often consider OBA as an invasive, annoying, disturbing type of advertising, capable of violating social norms. Several studies show a significant predisposition to avoid data-driven advertising for those who care about privacy in order to protect themselves from intrusive ads. In fact, the irritation produced by customized advertising, which requires the collection of personal data, increases skepticism about this type of advertising, which consequently leads to greater avoidance of the OBA (Baek and Morimoto, 2012; Smit et al., 2014; Lee et al., 2015). In addition, Ham (2017) states that the likelihood of a consumer to avoid the OBA may depend on the persuasive intent of marketers. Specifically, if consumers perceive the intent as manipulative, concerns about the invasion of one's privacy outweigh the possible benefits in terms of relevance, resulting in greater level of OBA avoidance (Ham, 2017). This is consistent with the privacy 
IJRDM

49,7

calculus described as a rational analysis of the balance between benefits and costs of disclosing personal data to a firm (Culnan and Armstrong, 1999; Plangger and Montecchi, 2020). Therefore, we posit the following hypothesis:

H4. The higher the level of privacy concerns about the OBA, the higher the level of avoidance of the OBA.

\section{8}

Acceptance and avoidance - click intention

One of the main pillars of the OBA resides in the practice of monitoring people's online behavior, namely, click intention responses to ads (Zuiderveen Borgesius, 2015; Boerman et al., 2017). Recent literature on OBA shows that among the outcomes of OBA, click intention is one of the main effects of advertising acceptance or avoidance.

On the one hand, the acceptance of the OBA, thanks to its level of personalization, relevance and perceived utility, seems to positively influence the level of click intention (Tucker, 2014; Aguirre et al., 2015; Bleier and Eisenbeiss, 2015a; Boerman et al., 2017). In addition, when the acceptance of the OBA is positively affected by transparency and consumer awareness of OBA, it alters consumers' responses to online behavioral ads, resulting in more click intention rates (Aguirre et al., 2015).

Conversely, when consumers are unaware that data are collected, they feel more vulnerable about privacy and avoid the OBA, which decreases their intention to click on OBA ads (Aguirre et al., 2015; Boerman et al., 2017). Thus, people experiencing lower usefulness, more reactance, and more privacy concerns are more likely to avoid the OBA, which explains the lower click-through intention.

In addition, the effects of OBA acceptance or avoidance on click intentions (Bleier and Eisenbeiss, 2015a; Boerman et al., 2017) are in line with the stimulus-organism-response model for which stimuli influence individuals' cognitive and affective responses, which then translate into specific behavior (Bleier and Eisenbeiss, 2015a; Jai et al., 2013; Boerman et al., 2017). In our research we considered "click intention" as a first consumer response, which that is then followed by behavioral intention operationalized as the intention of users to buy or not to buy: first consumers click on the advertisement and then they decide to buy or not a product or a service. Thus, we referred to click intention as an excellent predictor of the behavior of a consumer's purchasing process (Urban et al., 2014): intention to click could be a means for seeking further details or information about a product or a service, and in this way it could help users to browse the website to gain better information and carry out a detailed search on the website page. This could help users during their decision-making process. Therefore, if the level of click intention increases, the likelihood of purchasing a product increases. These considerations lead to the following hypotheses:

H5. The higher the level of acceptance of the OBA, the higher the level of click intention on the OBA.

H6. The higher the level of avoidance of the OBA, the lower the level of click intention on the OBA.

\section{Click intention - behavioral intention}

According to the theory of planned behavior (Ajzen, 1985, 1991), behavioral intention refers to the intention to perform a behavior that is the proximal cause of such a behavior. Specifically, intentions represent motivational components of a behavior, that is, the degree of conscious effort that a person will exert in order to perform a behavior (Ajzen, 1985). As far as OBA is concerned, behavioral intention refers to the likelihood that users would click on the ads and make a product purchase. Literature, in fact, has examined the effects of OBA on purchase 
intentions and actual purchases, identifying them as the measures of OBA effectiveness. Specifically, the intention to click is an excellent predictor of the behavioral one in the stage of a consumer's purchasing process (Urban et al., 2014): if the level of click intention increases, the likelihood of purchasing a product increases.

In addition, the relationship between click intention and behavioral intention is more effective, resulting in higher probability of purchase, when the ad fits consumers' needs (Van Doorn and Hoekstra, 2013) and even more when consumers' preferences are more carefully defined and they focus more on specific and detailed information (Lambrecht and Tucker, 2013).

These findings are in line with the stimulus-organism-response model, for which the intention to use ads in the future to make purchases (i.e. the response) is positively influenced by the intention to click on the ads with respect to the awareness of the benefits of the OBA due to the relevance, usefulness and credibility of personalized messages (i.e. the stimulus) (Bleier and Eisenbeiss, 2015a; Jai et al., 2013; Boerman et al., 2017). Therefore, the OBA can increase click intention rates and purchases of the product offering promoted by the OBA, resulting in the following hypothesis:

H7. The higher the level of click intention on the OBA, the higher the level of behavioral intention to purchase the product offering promoted by the OBA.

\section{Methodology \\ Sample}

To test all the hypotheses, we used a cross-sectional data analysis based on data collection using an online questionnaire with the belief that consumers who surf the web represent the most suitable target for the research objectives. In fact, those who are used to surfing online are most likely more familiar to new modes of digital communication. We requested them to answer to a structured questionnaire after being subjected to a visual stimulus, which represented an example of online behavioral advertising. A total of 128 subjects were interviewed, and Table 1 shows the demographic characteristics of the sample.

\section{Procedure}

First, we subjected each respondent to a visual stimulus (Figure 2) representing an example of online behavioral advertising associated with the decision-making process of searching for a product on a company's website. Specifically, the company considered in the research is Zalando, a European leading online fashion platform. Founded in 2008 in Berlin, Zalando has grown from a pioneer in e-commerce to becoming the most innovative fashion platform in Europe that delivers to customers in 17 countries with a wide assortment from more than 3,000 brands. As far as our research is concerned, Zalando was only used as an example of OBA advertising, and we decided to select it because in the fashion market in Italy, zalando.it is ranked at the first place with more than US\$500 $\mathrm{m}$ in 2019. Therefore, zalando.it accounts for $10-15 \%$ of e-commerce net sales in this category, and its website is widely used for the purchase of clothing (EcommerceDb, 2019). Therefore, because it might be known to most of our online respondents, we believed that Zalando was the most suitable company for our research. After the stimulus, shoppers answered to questions regarding their attitude toward the online behavioral advertising such as relevance, perceived usefulness and credibility of this type of advertising. In all, $93.8 \%$ of our respondents recognized the personalized advertisements proposed in the research. This allowed us to understand how the OBA phenomenon is evident to consumers.

Furthermore, considering the goals of our research, it was necessary to measure both the consumers' level of privacy concerns and their intention to accept or avoid the OBA. Finally, 
IJRDM 49,7

1100

we requested respondents to answer to questions regarding their intention to click to the ads and their actual intention to purchase the product sponsored by the OBA.

\section{Measures}

We measured all the variables considered with multiple-item scales, with the exception of the click intention, with Likert measurement scale from 1 (disagree) to 7 (agree). Specifically, all the scales used in the online survey come from previous research about shoppers and advertising theories and, once translated into Italian, were adapted to our model. Specifically, $O B A$ perceived usefulness considered four items adapted from Tam and Ho (2006), OBA

\section{Table 1.}

Demographic

characteristics of the sample

\begin{tabular}{llc}
\hline Characteristics & & Percentage \\
\hline Gender & Male & 39.8 \\
& Female & 60.2 \\
Age & Under 20 & 1.6 \\
& $20-24$ & 28.1 \\
& $25-29$ & 34.4 \\
& $30-34$ & 6.3 \\
& $35-44$ & 14.8 \\
& $45-54$ & 7.8 \\
& $55-65$ & 5.4 \\
& Over 65 & 1.6 \\
\hline
\end{tabular}

"Imagine that you want to buy a pair of sports shoes. In order to achieve this goal, you connect to the website "Zalando". Looking for "Running Sport Shoes", the site shows you different products. Browsing among the options, |you choose to click on some products to observe with greater attention.

I ask you to see this short video (25 seconds), in order to put yourself in the action just described, pretending to be you to operate the navigation.

Imagine then to leave the site without finalize the purchase. Imagine that the day after, browsing the web, you open the website of 3BMETEO.COM, finding yourself in front of an announcement advertising that shows the exact products that you have displayed during the navigation of the day previous."

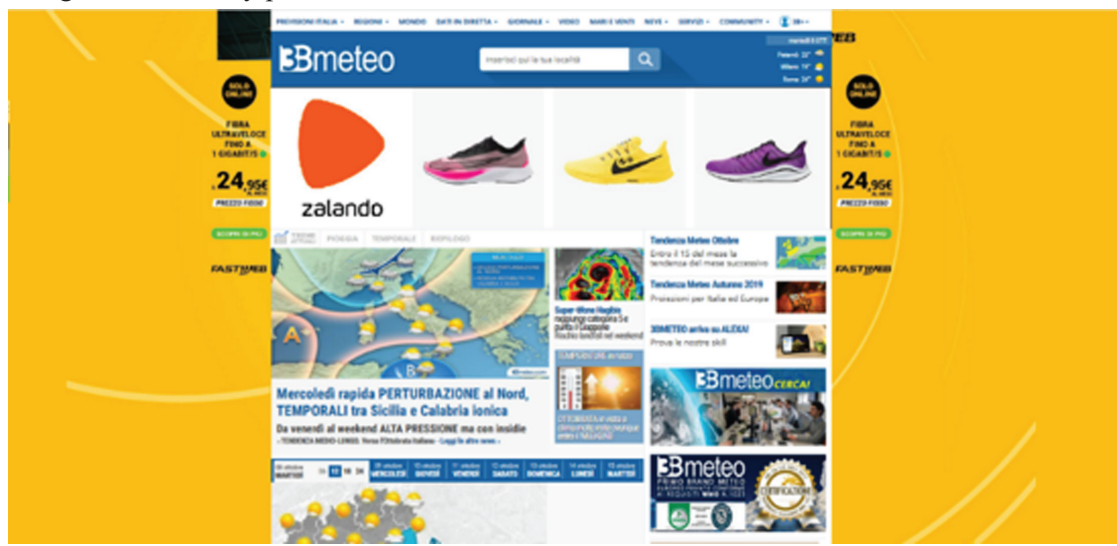

Figure 2.

Visual stimulus 
relevance was measured through eight items adapted from Laczniak and Muehling (1993) and $O B A$ credibility considered three items adapted from Tsang et al. (2004). Furthermore, the level of privacy concern was measured through five items adapted from Bleier and Eisenbeiss (2015a) and Dinev and Hart (2006), the OBA acceptance considered a two-items scale adapted from McDonald and Cranor (2010) and Turow et al. (2009), while the six-item scale of $O B A$ avoidance was drawn from Cho and Cheon (2004) and Speck and Elliott (1997). Finally, the behavioral intention to purchase the product promoted by OBA was measured by three items adapted from Taylor et al. (2011), while the click intention considered only a single item derived and adapted from Yoo (2007). Table 2 shows the scales with all the items and relative measures of reliability and validity.

\section{Findings}

We used a structural equation modeling (SEM) approach with partial least square (PLS) regression method and software SmartPLS 3.2.9 to test the research hypotheses (Fornell and Bookstein, 1982; Abdi, 2007). We considered our sample of 128 respondents as "acceptable," even if limited, as suggested by prior researchers (Boomsma, 1982, 1985). Furthermore, we used PLS and not LISREL or other software to test our structural equation model because PLS is useful specially when the distribution is not normal, and the sample size is not that big or is at least 10 times the maximum number of indicators of a latent variable (Hair et al., 2016).

For each construct, except for click intention [2], the adequacy of the individual items and the composites were assessed by measures of reliability (Santos, 1999), convergent validity (Anderson and Gerbing, 1988) and discriminant validity (Fornell and Larcker, 1981; Beatty and Ferrell, 1998).

First, we tested reliability using Cronbach's alpha and eliminated the items that would cause the worsening of the scale (Santos, 1999): all values are higher than the minimum acceptable value of 0.70 (see Table 2). Secondly, to test the convergent validity of our measures, we examined the significance of factor loadings (Anderson and Gerbing, 1988) and the composite reliability. Furthermore, the discriminant validity was evaluated by comparing the extracted variance (AVE) with the square of the correlation between the two latent variables considered (Fornell and Larcker, 1981). All the result indicates that the measurement model has adequate reliability, convergent validity and discriminant validity (Table 3).

As suggested by Hair et al. (2011) and Ramayah et al. (2016), we measured $R$ squares $\left(R^{2}\right)$ for all the latent variables in order to determine the goodness of the structural model. The overall fit of the structural model is good with all the fit indexes in line with the recommended values (Table 4).

The results of the path analysis are shown in Figure 3 with all the path coefficients (intensity and direction of relations) and the significance ( $t$-value) for each of them, while Table 5 summarizes the SEM results.

Results allow us to support the majority of our hypothesis, except for H3 $(\gamma=0.139$, $p$-value $>0.05)$ and H6 $(\beta=-0.113, p$-value $>0.05)$ (Table 4$)$. Specifically, the final SEM allows us to confirm the evidence of a positive and direct effect of the relevance (H1: $\gamma=0.321$, $p$-value $<0.01)$ and the credibility $(\mathrm{H} 2: \gamma=0.266, p$-value $<0.01)$ of the contents promoted by the OBA on the acceptance of the personalized advertising. This results in a more click intention rate $(\mathrm{H} 5: \beta=0.453, p$-value $<0.001)$ and consequently in a positive behavioral intention in terms of actual purchase behavior $(\mathrm{H} 7: \beta=0.643, p$-value $<0.001)$. In addition, the model confirms how the consumers' privacy concerns about data-driven advertising positively affect the intention to avoid the adoption of OBA (H4: $\gamma=0.496$, $p$-value $<0.001)$ resulting in a lower level of click intention rate (H6). Despite the negative effect of OBA avoidance on click intention, this ultimate relationship is not statistical significant. One 
IJRDM 49,7

1102

Scale items
OBA acceptance (adapted from McDonald and Cranor, 2010;
Turow et al., 2009)
(1) I prefer advertisements that reflect my interests
(2) For me it's ok to see personalized advertisements based on
my online browsing history

OBA avoidance (adapted from Cho and Cheon, 2004; Speck and Elliott, 1997)

(1) Intentionally, I ignore any customized advertisement

(2) I hate any customized advertisement

(3) It would be better if there were no customized advertisements

(4) I tried to set an "ad blocker" (program that blocks the display of advertisements on the web) to avoid customized advertisements

(5) I looked for help in order to prevent and avoid receiving customized advertisements

(6) I usually exit the web page I'm visiting not to see personalized advertisements

Behavioral intention (adapted from Taylor et al., 2011)

(1) I will use customized ads to shop whenever I have the option

(2) I want to use customized ads to shop, right after I see them

(3) I expect to use customized ads to buy products right after viewing them

OBA credibility (adapted Tsang et al., 2004)

(1) I consider customized ads as a shopping benchmark

(2) I trust customized ads

(3) Content provided by customized ads is credible

Privacy concerns (adapted from Bleier and Eisenbeiss, 2015a; Dinev and Hart, 2006)

(1) It bothers me that companies are able to track information about my online activity

(2) I worry that companies have so much information about me

(3) It bothers me that companies are able to access information about me

(4) I'm worried that my information can be used in ways that I cannot predict

(5) I worry what others might do with the history of my online activity

OBA relevance (adapted from Laczniak and Muehling, 1993)

(1) I feel that customized ads have value to me

(2) I feel that customized ads are relevant to my needs

(3) I think customized ads were created just for me

(4) I think it's worth paying attention to customized ads

(5) I think customized ads deserve to be remembered

(6) I think customized ads are useful for me

(7) I think customized ads are interesting

(8) I think customized ads will probably give me new ideas

\begin{tabular}{cccc}
$\begin{array}{c}\mathrm{N}^{\circ} \\
\text { items }\end{array}$ & $\begin{array}{c}\text { Cronbach's } \\
\text { alpha }\end{array}$ & $\mathrm{Cr}$ & AVE \\
\hline 2 & 0.724 & 0.879 & 0.784
\end{tabular}

6

0.826

$0.867 \quad 0.528$

3

0.940

$0.961 \quad 0.893$

3

0.828

$0.897 \quad 0.744$

5

0.956

$0.966 \quad 0.850$

8

0.932

$0.946 \quad 0.693$

\author{
(1)
}




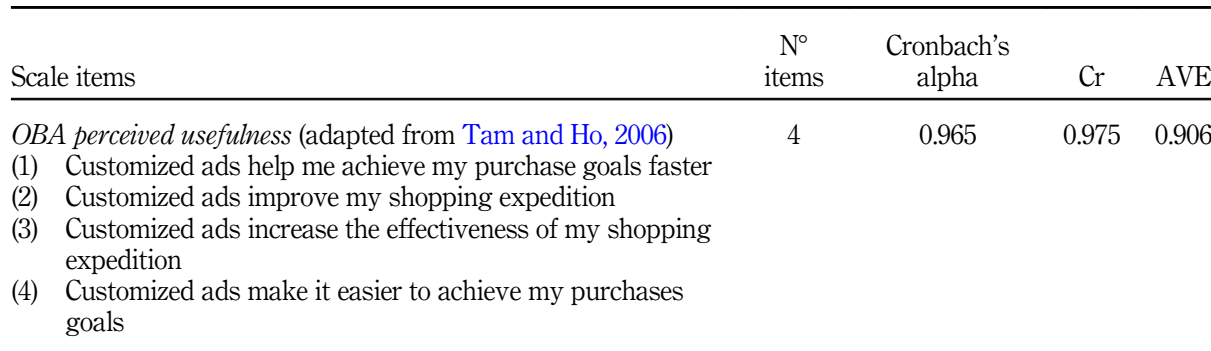

Data-driven digital advertising

$O B A$ perceived usefulness (adapted from Tam and Ho, 2006)

(2) Customized ads improve my shopping expedition

Customized ads increase the effectiveness of my shopping

Customized ads make it easier to achieve my purchases

\begin{tabular}{lrrrrrrrr}
\hline & 1 & 2 & 3 & 4 & 5 & 6 & 7 & 8 \\
\hline 1. OBA acceptance & 0.885 & & & & & & & \\
2. OBA avoidance & -0.141 & 0.726 & & & & & & \\
3. Behavioral intention & 0.526 & -0.258 & 0.945 & & & & & \\
4. Click intention & 0.469 & -0.177 & 0.643 & 1.000 & & & & \\
5. OBA credibility & 0.554 & -0.332 & 0.732 & 0.55 & 0.862 & & & \\
6. Privacy concerns & -0.066 & 0.496 & -0.174 & -0.009 & -0.307 & 0.922 & & \\
7. OBA relevance & 0.606 & -0.394 & 0.681 & 0.504 & 0.690 & -0.113 & 0.833 & \\
8. OBA perceived & 0.498 & -0.260 & 0.542 & 0.331 & 0.474 & 0.008 & 0.726 & 0.952
\end{tabular}
usefulness

Note(s): On the diagonal: square root of AVEs. Below the diagonal: correlations. The square roots of AVEs (in italic) are larger than off-diagonal elements in their corresponding row and column for all cases

Table 3.

Convergent validity analysis results and correlations

\begin{tabular}{lr}
\hline Latent variable & $R^{2}$ \\
\hline OBA acceptance & 0.411 \\
OBA avoidance & 0.246 \\
Behavioral intention & 0.414 \\
Click intention & 0.232
\end{tabular}

Note(s): All latent variables have their $R$ squares greater than $15 \%$, suggesting good predictability of our model as confirmed by Chin (1998)

Table 4. Fit of the model $-R^{2}$

possible justification might come from the privacy paradox: although people say they care about their privacy and are not willing to share their information, actually they give their data in exchange for small benefits or for convenience (Norberg et al., 2007). Therefore, although people say they are opposed to the OBA because of privacy risks, people express the opposite and click on the advertising.

Finally, despite the positive effect of OBA usefulness on OBA acceptance, our model shows that this relationship is not statistical significant. This may be a consequence of the fact that the perceived usefulness of the ad may have been affected by the level of familiarity of users with the context in which the personalized ad is inserted, namely, the Zalando company. In fact, according to literature, as far as OBA is concerned, perceived usefulness refers to the extent users believe OBA and relevant personalized ads will help them perform better based on their own purposes. If they do not know Zalando, they may not find the proposed ad useful. If consumers are not familiar with the company, it becomes difficult for them to evaluate the level of usefulness. Thus, the direction (positive effect) of the relationship is consistent with what is stated in literature on the relationship between perceived 


\section{IJRDM \\ 49,7}

1104

Figure 3.

Structural model

\section{Table 5.}

Summary structural model

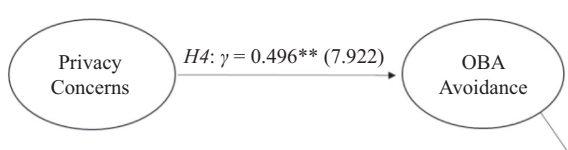

$H 6: \beta=-0.113^{\text {ns }}(1.154)$
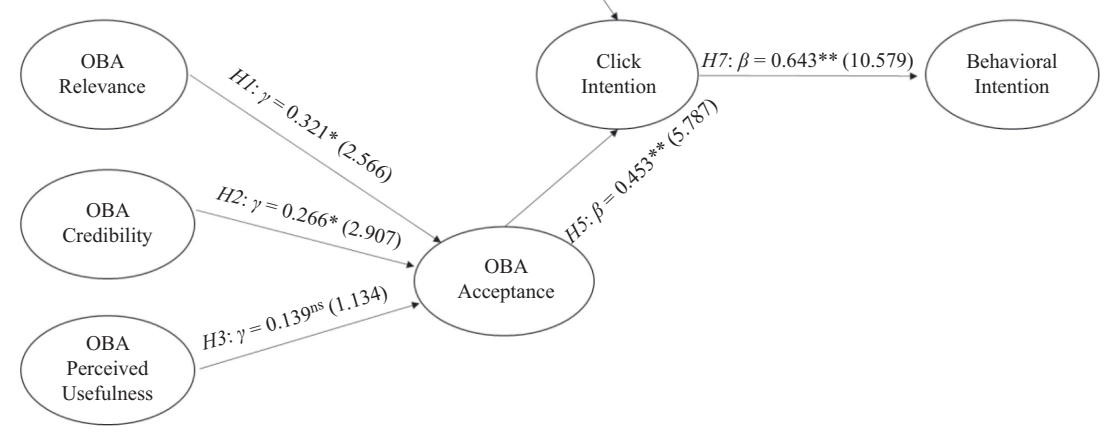

Note(s): ${ }^{* *}: p$-value $<0.001 ; *$ : $p$-value $<0.01 ;$ ns: $p$-value $>0.05$

\begin{tabular}{lrrrrc}
\hline Hypothesis & Coeff & St. dev & $T$-value & $P$-value & Hypothesis \\
\hline H1: OBA relevance $\rightarrow$ OBA acceptance & 0.321 & 0.125 & 2.566 & 0.011 & Accepted \\
H2: OBA credibility $\rightarrow$ OBA acceptance & 0.266 & 0.092 & 2.907 & 0.004 & Accepted \\
H3: OBA perceived usefulness $\rightarrow$ OBA acceptance & 0.139 & 0.122 & 1.134 & 0.257 & Rejected \\
H4: Privacy concerns $\rightarrow$ OBA avoidance & 0.496 & 0.063 & 7.922 & 0.000 & Accepted \\
H5: OBA acceptance $\rightarrow$ Click intention & 0.453 & 0.078 & 5.787 & 0.000 & Accepted \\
H6: OBA avoidance $\rightarrow$ Click intention & -0.113 & 0.098 & 1.154 & 0.249 & Rejected \\
H7: Click intention $\rightarrow$ Behavioral intention & 0.643 & 0.061 & 10.579 & 0.000 & Accepted \\
\hline
\end{tabular}

usefulness and the effectiveness of OBA (Davis, 1989; Bleier and Eisenbeiss, 2015a; Boerman et al., 2017). However, in our model, the significance of the relationship is not proved maybe because of the influence exerted by the familiarity with the company used as the example of OBA.

\section{Conclusions and implications}

Our research makes a number of theoretical contribution and significant managerial implications. On the theoretical perspective, our work may contribute to advance the state of knowledge about personalized and data-driven digital advertising and its application in the new online retail environment. Prior research came up with theoretical frameworks that explain antecedents of OBA focusing only on ethical issues in marketing (Boerman et al., 2017) or only on the effectiveness of a single OBA campaign or how to create a successful advertising campaign (Varnali, 2019). Literature identifies factors controlled by advertisers and factors controlled by consumers in order to create comprehensive theoretical frameworks of the effectiveness of the OBA. However, besides being complex models, no study focuses on the intended or actual behavior of shoppers. Specifically, any research applies an SEM approach in order to identify the antecedents of the actual behavior of individuals in terms of actual purchases of products or services promoted by OBA. Filling the gap in the existing literature, the research, through an SEM approach, seeks to build up a simplified model that considers both the benefits (relevance, credibility 
and perceived usefulness of personalized online behavioral advertising) and the risks (privacy and ethical concerns) of the OBA.

According to prior studies, our research demonstrates how OBA is a controversial type of advertising. In fact, it activates opposing reactions on consumers' perspective: relevance, usefulness and credibility on the one hand, and concerns and intrusiveness on the other. Acceptance of the OBA is positively related to the relevance and the credibility of the personalized advertisements, intended as the reliability and capability of the OBA of being a significant guide into the purchasing process, while the intention to avoid personalized ads is strictly related to the concerns for privacy. Consequently, acceptance and avoidance of OBA affected (positively and negatively respectively) the intention to click on the ad and the behavioral intention confirming a direct effect of click intention on behavioral intention, signal that they are decisive for the success of the data-driven digital advertising. Specifically, as far as OBA is concerned, behavioral intention refers to the likelihood that users would click on the ads and make a product purchase. Thus, our findings are consistent with literature that examined the effects of OBA on purchase intentions and actual purchases and identified the intention to click as an excellent predictor of the behavior in the stage of a consumer's purchasing process (Urban et al., 2014): if the level of click intention increases, the likelihood of purchasing a product increases, and vice versa.

On the managerial perspective, the research suggests marketers to focus attention on relevance and credibility of advertising messages rather than worry about privacy.

Although concern for privacy is one of the central problems for the digital advertising industry as well as one of the negative effects of the OBA, our findings show that privacy affects OBA acceptance, but this, in turn, has no effect on click intention. This result can be consistent with the possible effect of the so-called privacy paradox, that is, that people say they care about their privacy and are not willing to share their information, but actually, they give their data in exchange for small benefits or for convenience (Norberg et al., 2007). Thus, although people say they are opposed to the OBA, they do not take measures to protect their data and they click on the ads or accept cookies managed by websites. Therefore, people are worried by privacy risks, but express the opposite. Thus, negative perceptions about the OBA are not in line with consumers' actual behavior or their expectations (Boerman et al., 2017). However, due to its privacy implications, the OBA will soon enter the political agenda of several states, forcing companies to increase transparency and ensure greater data protection (Boerman et al., 2017).

Our research should help advertisers consider the level of ad personalization since ads perceived as too personal could be perceived as too intrusive and, consequently, lead to lower levels of click intentions and purchases. Consumers, indeed, will tend to accept OBA only if the benefits outweigh the costs. Therefore, our research suggests marketers to invest in the relevance and credibility of OBA messages.

Specifically, the topic of relevance underlines the importance of big data analytics, a necessary condition for creating personalized content and messages. Therefore, as a result of digitalization, it becomes essential for companies to invest in big data analytics and hire specialized personnel able to manage the personalization of data-driven digital advertising.

In addition, the positive effect of the message's credibility on OBA acceptance suggests companies pay attention to the choice of information sources and intermediaries, especially nowadays when the consumer is more informed, critical and wary. In this panorama emerges the figure of the influencer, often considered more credible and reliable than the company itself, to which companies could turn in the future to improve the credibility of messages conveyed to the market.

To conclude, the Internet and new media have changed individuals' habits and the way they use advertising messages, revolutionizing the way companies invest, promote and
Data-driven digital advertising

1105 
IJRDM 49,7

define measurement metrics, and despite its negative effects, personalized and data-driven digital advertising seems to be the future of advertising.

\section{Limitations and future research}

Some limitations are associated with the online survey and the sample size. First, respondents may have been influenced by the presence of the visual stimulus and then distorted the answers in order to accomplish the research. Another concern is about the generalizability of the results. Our sample, interviewed online, is probably neither truly random nor necessarily representative of any larger population. Although some authors identified our sample of 128 respondents as acceptable for a PLS approach to structural equation model (Boomsma, 1982, 1985; Hair et al., 2016), we intend, for future research, to enlarge the sample.

In addition, some relationships in our model may have been influenced by the level of familiarity of users with the context in which the personalized ad is inserted, namely, the Zalando company. Specifically, if respondents are not familiar with the company, it becomes difficult for them to evaluate the level of usefulness of the personalized ad. This limit should be overcome by measuring the familiarity with the company presented in the ad or keeping under control its effects with an experimental approach. This latter approach could let research overcome other limitations related to the proposed research and contextual aspects such as the effect of the level of consciousness of targeting tactic. In the proposed model, we are not able to measure the different levels of consciousness of the targeting tactic, and so we cannot include this variable in this specific mode. However, we intend to consider this issue in future research and future SEM models by considering the level of consciousness of the targeting tactic (or better the awareness of the OBA tactic) as a moderator or control variable. Our study, in fact, is a type of stimulusresponse model based on framing a situation, but no comparisons are provided with a frameless approach. This is a weakness of the methodology that should be overcome through experimental approach. In addition, in order to simplify the model, we considered only the most cited variables and potentially we may have overlooked other variables affecting the outcomes of the OBA. For example, consumers' perception of the OBA might also depend on individual characteristics, such as age or familiarity with the online environment. Specifically, future research should investigate if younger people are less likely to avoid the OBA compared to older ones, or vice versa. In addition, researchers might investigate deeply if the OBA has a positive effect on people with high levels of online experience and vice versa, or if its effects might change according to different levels of privacy concerns.

Finally, we invite all the researchers who want to investigate this topic to adopt a general framework on digital communications that could grant an excellent opportunity for a deeper discussion of related topics that might be considered in the effect of OBA on purchase intentions such as multiple touchpoints, attribution, social media and influencer marketing.

\section{Notes}

1. Definition of digital marketing by AMA is available at (https://www.ama.org/AboutAMA/Pages/ Definition-of-Marketing.aspx).

2. The value of single-item constructs has been debated in literature; however, single-item constructs were found as good at capturing the nature of the phenomenon in question (Gardner and Cummings, 1998).

\section{References}

Abdi, H. (2007), "Partial least square regression", in Neil, S. (Ed.), Encyclopedia of Measurement and Statistics, Sage, Thousand Oaks, California. 
Aguirre, E., Mahr, D., Grewal, D., De Ruyter, K. and Wetzels, M. (2015), "Unraveling the personalization paradox: the effect of information collection and trust-building strategies on online advertisement effectiveness", Journal of Retailing, Vol. 91 No. 1, pp. 34-49.

Ajzen, I. (1985), "From intentions to actions: a theory of planned behaviour", in Action Control, Springer, Berlin, Heidelberg, pp. 11-39.

Ajzen, I. (1991), "The theory of planned behaviour", Organizational Behavior and Human Decision Processes, Vol. 50 No. 2, pp. 179-211.

Anderson, J.C. and Gerbing, D.W. (1988), "Structural equation modeling in practice: a review and recommended two-step approach”, Psychological Bulletin, Vol. 103 No. 3, pp. 411-423.

Baek, T.H. and Morimoto, M. (2012), "Stay away from me: examining the determinants of consumer avoidance of personalized advertising", Journal of Advertising, Vol. 41 No. 1, pp. 59-76.

Beatty, S. and Ferrell, E. (1998), "Impulse buying: modeling its precursors", Journal of Retailing, Vol. 74 No. 2, pp. 169-191, doi: 10.1016/s0022-4359(99)80092-x.

Bellman, S., Murphy, J., Treleaven-Hassard, S., O’Farrell, J., Qiu, L. and Varan, D. (2013), "Using internet behavior to deliver relevant television commercials", Journal of Interactive Marketing, Vol. 27, pp. 130-140.

Bleier, A. and Eisenbeiss, M. (2015a), "The importance of trust for personalized online advertising", Journal of Retailing, Vol. 91 No. 3, pp. 390-409.

Bleier, A. and Eisenbeiss, M. (2015b), "Personalized online advertising effectiveness: the interplay of what, when, and where", Marketing Science, Vol. 34 No. 5, pp. 669-688.

Boerman, S.C., Kruikemeier, S. and Zuiderveen Borgesius, F.J. (2017), "Online behavioral advertising: a literature review and research agenda”, Journal of Advertising, Vol. 46 No. 3, pp. 363-376.

Boomsma, A. (1982), "The robustness of LISREL against small sample sizes in factor analysis models", Systems under Indirect Observation: Causality, Structure, Prediction, pp. 149-173.

Boomsma, A. (1985), "Nonconvergence, improper solutions, and starting values in LISREL maximum likelihood estimation”, Psychometrika, Vol. 50 No. 2, pp. 229-242.

Brettel, M., Reich, J.C., Gavilanes, J.M. and Flatten, T.C. (2015), "What drives advertising success on Facebook? An advertising-effectiveness model: measuring the effects on sales of 'likes' and other social-network stimuli”, Journal of Advertising Research, Vol. 55 No. 2, pp. 162-175.

Bucklin, R.E. and Sismeiro, C. (2009), "Click here for internet insight: advances in clickstream data analysis in marketing", Journal of Interactive Marketing, Vol. 23 No. 1, pp. 35-48.

Chin, W.W. (1998), "The partial least squares approach to structural equation modeling", Modern Methods for Business Research, Vol. 295 No. 2, pp. 295-336.

Cho, C.H. and Cheon, H.J. (2004), "Why do people avoid advertising on the internet?", Journal of Advertising, Vol. 33 No. 4, pp. 89-97.

Culnan, M.J. and Armstrong, P.K. (1999), "Information privacy concerns, procedural fairness, and impersonal trust: an empirical investigation", Organization Science, Vol. 10 No. 1, pp. 104-115.

Davis, F.D. (1989), "Perceived usefulness, perceived ease of use, and user acceptance of information technology", MIS Quarterly, Vol. 13 No. 3, pp. 319-340.

Dinev, T. and Hart, P. (2006), "Internet privacy concerns and social awareness as determinants of intention to transact", International Journal of Electronic Commerce, Vol. 10 No. 2, pp. 7-29.

EcommerceDb (2019), available at: https://ecommercedb.com/en/store/zalando.it (accessed Februrary 2021).

eMarketer (2019), "Digital ad spending global (2019)", available at: https://www.emarketer.com/ content/global-digital-ad-spending-2019 (accessed September 2020).

eMarketer (2020), "Global digital ad spending update q2 2020", available at: https://www.emarketer. com/content/global-digital-ad-spending-update-q2-2020 (accessed October 2020).

Emerson, R.M. (1976), "Social exchange theory”, Annual Review of Sociology, Vol. 2 No. 1, pp. 335-362.
Data-driven digital advertising 
IJRDM 49,7

1108

Fornell, C. and Bookstein, F.L. (1982), "Two structural equation models: LISREL and PLS applied to consumer exit-voice theory", Journal of Marketing Research, Vol. 19, pp. 440-452.

Fornell, C. and Larcker, D.F. (1981), "Evaluating structural equation models with unob- servable variables and measurement error", Journal of Marketing Research, Vol. 18 No. 2, pp. 39-50.

Gardner, D.G. and Cummings, L.L. (1998), "Single-item versus multiple-item measurement scales: an empirical comparison”, Educational and Psychological Measurement, Vol. 58 No. 6, pp. 898-915.

Ghose, A. and Todri, V. (2015), "Towards a digital attribution model: measuring the impact of display advertising on online consumer behavior", available at SSRN 2672090.

Gironda, J.T. and Korgaonkar, P.K. (2018), "iSpy? tailored versus invasive ads and consumers' perceptions of personalized advertising", Electronic Commerce Research and Applications, Vol. 29, pp. 64-77.

Goldfarb, A. and Tucker, C.E. (2011), "Online display advertising: targeting and obtrusiveness", Marketing Science, Vol. 30, pp. 389-404.

Guo, B. and Sismeiro, C. (2020), "Between click and purchase: predicting purchase decisions using clickstream data", Advances in Consumer Research, Vol. 47, pp. 608-609.

Hair, J.F., Jr, Hult, G.T.M., Ringle, C. and Sarstedt, M. (2016), A Primer on Partial Least Squares Structural Equation Modeling (PLS-SEM), Sage Publications, New York.

Hair, J.F., Ringle, C.M. and Sarstedt, M. (2011), "PLS-SEM: indeed a silver bullet", Journal of Marketing Theory and Practice, Vol. 19 No. 2, pp. 139-152.

Ham, C.D. (2017), "Exploring how consumers cope with online behavioral advertising", International Journal of Advertising, Vol. 36, pp. 632-658.

Ham, C.D. and Nelson, M.R. (2016), "The role of persuasion knowledge, assessment of benefit and harm, and third-person perception in coping with online behavioral advertising", Computers in Human Behavior, Vol. 62, pp. 689-702.

Jai, T.M.C., Burns, L.D. and King, N.J. (2013), "The effect of behavioral tracking practices on consumers' shopping evaluations and repurchase intention toward trusted online retailers", Computers in Human Behavior, Vol. 29 No. 3, pp. 901-909.

Jain, A.K. (2007), "Biometric recognition”, Nature, Vol. 449 No. 7158, pp. 38-40.

Kannan, P.K. (2017), "Digital marketing: a framework, review and research agenda", International Journal of Research in Marketing, Vol. 34 No. 1, pp. 22-45.

Kerr, G.B. and Richards, J.I. (2020), "Redefining advertising in research and practice”, International Journal of Advertising, Vol. 40 No. 2, pp. 1-24, doi: 10.1080/02650487.2020.1769407.

Laczniak, R.N. and Muehling, D.D. (1993), "The relationship between experimental manipulations and tests of theory in an advertising message involvement context", Journal of Advertising, Vol. 22 No. 3, pp. 59-74.

Lamberton, C. and Stephen, A.T. (2016), "A thematic exploration of digital, social media, and mobile marketing: research evolution from 2000 to 2015 and agenda for future inquiry", Journal of Marketing, Vol. 80, pp. 146-172.

Lambrecht, A. and Tucker, C. (2013), "When does retargeting work? Information specificity in online advertising", Journal of Marketing Research, Vol. 50 No. 5, pp. 561-576.

Lee, S., Lee, Y., Lee, J. and Park, J. (2015), "Personalized e-services: consumer privacy concern and information sharing", Social Behavior and Personality: International Journal, Vol. 43 No. 5, pp. 729-740.

Li, J., Luo, X., Lu, X. and Moriguchi, T. (2020), "The double-edged effects of e-commerce cart retargeting: does retargeting too early backfire?", Journal of Marketing, 0022242920959043.

Liberali, G.B., Hauser, J.R. and Urban, G.L. (2017), "Morphing theory and applications", in Handbook of Marketing Decision Models, Springer, Cham, pp. 531-562. 
Mardegan, P., Riva, G. and Scatena, S.F. (2016), Digital Advertising 3.0. Il futuro della pubblicità digitale, Maggioli Editore, Milano.

McDonald, A.M. and Cranor, L.F. (2010), "Beliefs and behaviors: internet users' understanding of behavioral advertising", TPRC 2010, available at: http://aleecia.com/authors-drafts/tprc-behavAV.pdf.

Miyazaki, A.D. (2008), "Online privacy and the disclosure of cookie use: effects on consumer trust and anticipated patronage”, Journal of Public Policy and Marketing, Vol. 27 No. 1, pp. 19-33.

Monem, A. and Nagy, H. (2021), "The effectiveness of advertising personalization”, Journal of Design digital advertising Sciences and Applied Arts, Vol. 2 No. 1, pp. 335-344.

Moore, R.S., Moore, M.L., Shanahan, K.J. and Mack, B. (2015), "Creepy marketing: three dimensions of perceived excessive online privacy violation”, Marketing Management, Vol. 25, pp. 42-53.

Norberg, P.A., Horne, D.R. and Horne, D.A. (2007), "The privacy paradox: personal information disclosure intentions versus behaviors", Journal of Consumer Affairs, Vol. 41 No. 1, pp. 100-126.

Ozcelik, A.B. and Varnali, K. (2019), "Effectiveness of online behavioral targeting: a psychological perspective", Electronic Commerce Research and Applications, Vol. 33, pp. 1-11.

Petty, R.E. and Cacioppo, J.T. (1986) The elaboration likelihood model of persuasion, in Communication and Persuasion, Springer, New York, New York, pp. 1-24.

Petty, R.E., Cacioppo, J.T. and Schumann, D. (1983), "Central and peripheral routes to advertising effectiveness: the moderating role of involvement”, Journal of Consumer Research, Vol. 10, pp. 135-146.

Phelan, C., Lampe, C. and Resnick, P. (2016), “It's Creepy, but it doesn't bother me”, Proceedings of the 2016 CHI Conference on Human Factors in Computing Systems, Association for Computing Machinery, New York, pp. 5240-5251.

Plangger, K. and Montecchi, M. (2020), "Thinking beyond privacy calculus: investigating reactions to customer surveillance", Journal of Interactive Marketing, Vol. 50, pp. 32-44.

Ramayah, T., Ling, N.S., Taghizadeh, S.K. and Rahman, S.A. (2016), "Factors influencing SMEs website continuance intention in Malaysia", Telematics and Informatics, Vol. 33 No. 1, pp. 150-164.

Sahni, N.S., Narayanan, S. and Kalyanam, K. (2019), "An experimental investigation of the effects of retargeted advertising: the role of frequency and timing", Journal of Marketing Research, Vol. 56 No. 3, pp. 401-418.

Santos, J.R.A. (1999), “Cronbach's alpha: a tool for assessing the reliability of scales”, Journal of Extention, Vol. 37 No. 2, pp. 1-5.

Schumann, J.H., von Wangenheim, F. and Groene, N. (2014), "Targeted online advertising: using reciprocity appeals to increase acceptance among users of free web services", Journal of Marketing, Vol. 78 No. 1, pp. 59-75.

Sinclair, J. (2016), "Advertising and media in the age of the algorithm", International Journal of Communication, Vol. 10, pp. 3522-3535.

Sismeiro, C. and Bucklin, R.E. (2004), "Modeling purchase behavior at an e-commerce web site: a taskcompletion approach", Journal of Marketing Research, Vol. 41 No. 3, pp. 306-323.

Smit, E.G., Van Noort, G. and Voorveld, H.A. (2014), "Understanding online behavioural advertising: user knowledge, privacy concerns, and online coping behaviour in Europe", Computers in Human Behavior, Vol. 32, pp. 15-22.

Speck, P.S. and Elliott, M.T. (1997), "Predictors of advertising avoidance in print and broadcast media", Journal of Advertising, Vol. 26 No. 3, pp. 61-76.

Summers, C.A., Smith, R.W. and Reczek, R.W. (2016), "An audience of one: behaviorally targeted ads as implied social labels", Journal of Consumer Research, Vol. 43 No. 1, pp. 156-178. 
IJRDM 49,7

1110

Sutanto, J., Palme, E., Tan, C. and Phang, C.W. (2013), “Addressing the personalization-privacy paradox: an empirical assessment from a field experiment on smartphone users", MIS Quarterly, Vol. 37 No. 4, pp. 1141-1164.

Tam, K.Y. and Ho, S.Y. (2006), "Understanding the impact of web personalization on user information processing and decision outcomes", MIS Quarterly, Vol. 30 No. 4, pp. 865-890.

Taylor, C.R. and Carlson, L. (2021), "The future of advertising research: new directions and research needs", Journal of Marketing Theory and Practice, Vol. 29 No. 1, pp. 1-12.

Taylor, D.G., Lewin, J.E. and Strutton, D. (2011), "Friends, fans, and followers: do ads work on social networks?”, Journal of Advertising Research, Vol. 51 No. 1, pp. 258-275.

Tsang, M.M., Ho, S.C. and Liang, T.P. (2004), "Consumer attitudes toward mobile advertising: an empirical study", International Journal of Electronic Commerce, Vol. 8 No. 3, pp. 65-78.

Tucker, C.E. (2014), "Social networks, personalized advertising, and privacy controls", Journal of Marketing Research, Vol. 51 No. 5, pp. 546-62.

Turow, J., King, J., Hoofnagle, C.J., Bleakley, A. and Hennessy, M. (2009), Americans Reject Tailored Advertising and Three Activities that Enable it, Annenberg School for Communication (U of Pennsylvania) and Berkeley School of Law, University of California, Berkeley, available at SSRN 1478214.

Ur, B., Leon, P.G., Cranor, L.F., Shay, R. and Wang, Y. (2012), "Smart, useful, scary, creepy: perceptions of online behavioral advertising", proceedings of the Eighth Symposium on Usable Privacy and Security, art. 4.

Urban, G.L., Liberali, G., MacDonald, E., Bordley, R. and Hauser, J.R. (2014), "Morphing banner advertising", Marketing Science, Vol. 33 No. 1, pp. 27-46.

Van Doorn, J. and Hoekstra, J.C. (2013), “Customization of online advertising: the role of intrusiveness", Marketing Letters, Vol. 24 No. 4, pp. 339-345.

Van Noort, G., Smit, E.G. and Voorveld, H.A. (2013), "The online behavioural advertising icon: two user studies", Advances in Advertising Research, Vol. 4, pp. 365-378.

Varnali, K. (2019), "Online behavioral advertising: an integrative review", Journal of Marketing Communications, Vol. 27 No. 1, pp. 1-22.

Wedel, M. and Kannan, P.K. (2016), "Marketing analytics for data-rich environments", Journal of Marketing, Vol. 80 No. 6, pp. 97-121.

Winter, S., Maslowska, E. and Vos, A.L. (2021), "The effects of trait-based personalization in social media advertising", Computers in Human Behavior, Vol. 114, 106525.

Yang, H. (2013), "Young American consumers' online privacy concerns, trust, risk, social media use, and regulatory support", Journal of New Communications Research, Vol. 5 No. 1, pp. 1-30.

Yoo, C.Y. (2007), "Implicit memory measures for web advertising effectiveness", Journalism and Mass Communication Quarterly, Vol. 84 No. 1, pp. 7-23.

Zuiderveen Borgesius, F.J. (2015), "Improving privacy protection in the area of behavioural targeting", Information Law Series, Vol. 33, pp. 1-14.

\section{Corresponding author}

Simone Aiolfi can be contacted at: simone.aiolfi@unipr.it

For instructions on how to order reprints of this article, please visit our website:

www.emeraldgrouppublishing.com/licensing/reprints.htm

Or contact us for further details: permissions@emeraldinsight.com 